Research Article

\title{
Investigation of Lade-Kim Plastic Potential Applicability under Various Stress Paths for Rockfill Materials
}

\author{
Liping Chen, ${ }^{1}$ Shihai Bian ${ }^{(D},{ }^{2}$ Xiaokai Niu, ${ }^{3}$ and Yongbo Zhao ${ }^{1}$ \\ ${ }^{1}$ School of Civil and Transportation Engineering, Ningbo University of Technology, Ningbo 315016, China \\ ${ }^{2}$ Zhejiang Engineering Survey and Design Institute Group Co., Ltd., Ningbo 315012, China \\ ${ }^{3}$ Beijing Municipal Engineering Research Institute, Beijing 100037, China \\ Correspondence should be addressed to Shihai Bian; bsh2013@tongji.edu.cn
}

Received 7 February 2021; Revised 25 July 2021; Accepted 25 August 2021; Published 15 September 2021

Academic Editor: Abílio De Jesus

Copyright (C) 2021 Liping Chen et al. This is an open access article distributed under the Creative Commons Attribution License, which permits unrestricted use, distribution, and reproduction in any medium, provided the original work is properly cited.

The dilatancy behavior of rockfill materials shows obvious stress path dependence. Lade-Kim plastic potential equation has been proposed for a long time to model the mechanical behavior of sand and concrete materials. However, it lacks the verification of rockfill materials, especially under various stress paths. In this paper, the dilatancy performance of coarse-grained materials under various stress paths is investigated, and then the dilatancy equation description and verification method based on Lade-Kim plastic potential are given. The applicability of Lade-Kim plastic potential for different stress path tests, such as conventional triaxial tests, constant $\mathrm{P}$ tests, and constant stress (increment) ratio tests, are verified and evaluated. It is found that Lade-Kim plastic potential is difficult to consider the influence of stress path. Finally, the Lade-Kim plastic potential, together with nonlinear dilatancy equation, is evaluated by changing the dilatancy equation in the framework of generalized plasticity. Lade-Kim plastic potential is suitable for constant stress increment ratio loading experiments and special care should be taken when applied to other stress paths. These works are helpful to understand stress path dependence of dilatancy behavior for rockfill materials and is beneficial for the establishment of stress path constitutive model.

\section{Introduction}

Rockfill is an important building material for high earth rockfill dam, and its deformation characteristics will significantly affect the safety of the dam. In the process of filling and impoundment, the actual stress path is a complex loading process with variable confining pressure. If the deformation characteristics of rockfill materials under complex loading paths can be described more accurately, it is beneficial to correctly evaluate the safety of high earth rockfill dam and its impervious body. The dilatancy equation is an important part of the elastoplastic constitutive model, and it is an important foundation to establish the constitutive model of rockfill materials which reflects the complex deformation characteristics. Investigating dilatancy characteristics of rockfill materials under various stress paths is beneficial to the establishment of stress path constitutive model.
Since Rowe [1] proposed the famous dilatancy equation, many domestic and foreign scholars have done a lot of research on the dilatancy equation. Nova and Wood [2] proposed a nonlinear dilatancy equation, and then Jefferies [3] analyzed Nova dilatancy equation from the perspective of energy. Some domestic scholars, such as Zhang et al. [4], Wang et al. [5], and Jia et al. [6], have also put forward modified dilatancy equations for rockfill materials. The experimental study of Cheng et al. [7] shows that Rowe dilatancy equation can better reflect the dilatancy characteristics of coarse-grained soil. Liu et al. [8] studied the dilatancy law of rockfill materials with different initial void ratios. By incorporating grain-crushing into critical state line and dilatancy equation, $\mathrm{Hu}$ et al. [9] establish constitutive models for rockfill materials considering particle breakage. Jia et al. [10] discussed particle breakage of rockfill material during triaxial tests under complex stress paths. Guo and Zhu [11] considered particle breakage effect in energy 
consumption and deduce dilatancy law of rockfill materials. Liu et al. [12], Liu et al. [13], Zhang et al. [14], Gu et al. [15], Yang et al. [16], and Chen et al. [17] studied the stress deformation characteristics of rockfill materials under different stress paths. However, the work of dilatancy characteristics for rockfill materials mainly focuses on constant confining pressure $\sigma 3$ stress path. Less attention was paid to dilatancy law of rockfill materials along other loading stress paths.

Lade and Kim [18-21] put forward the classic Lade-Kim model for a long time. Its plastic potential is relatively simple and has good application in sand and concrete tests. It has good adaptability to some stress paths. However, there is a lack of Lade-Kim plastic potential to verify the triaxial experiments of rockfill materials. At the same time, the applicability of Lade-Kim plastic potential for different stress path tests, such as conventional triaxial tests, constant $\mathrm{P}$ tests, and constant stress (increment) ratio tests, should be verified and evaluated.

The objectives of this paper are (1) to analyze the dilatancy characteristics of rockfill materials under different stress paths; (2) to study the adaptability of the dilatancy equation derived from Lade-Kim plastic potential surface for different stress paths and compare Lade-Kim plastic potential parameters for multiple stress path tests; and (3) to apply Lade-Kim plastic potential in generalized plasticity model to predict rockfill materials triaxial test and evaluate its performance by making comparison with nonlinear dilatancy equation.

\section{Dilatancy Equation for Different Loading Stress Paths}

In order to explore the dilatancy equation of rockfill under different stress paths, the data of conventional triaxial, constant $\mathrm{P}$ tests and constant stress ratio tests were summed to analyze and compare the dilatancy equation of rockfill materials under various stress path experiments.

\subsection{Analysis of Dilatancy Equation under Different Stress} Paths. For conventional triaxial tests of rockfill materials, various dilatancy equations were proposed, such as linear dilatancy equation [22], Rowe dilatancy equation [1], modified Cambridge dilatancy equation [23], and Fu's dilatancy equation [24]. Few people pay attention to dilatancy equation under other stress paths, and the dilatancy equation derived from conventional triaxial tests is often applied into such paths in model verification. It is necessary to study the dilatancy equation of rockfill materials under various stress paths.

The test results of sand by Sik-Cheung Robert Lol and Ian Kenneth Lee [25] are shown in Figure 1. Stress path directions are defined in the literature, which is $R=d \sigma_{1} / d \sigma_{3} . R=\infty$ means constant $\sigma 3$ test which is also called conventional triaxial test; $R=-2$ means constant $\mathrm{P}$ test; $R=0$ means constant $\sigma 1$ test; $R=4$ means constant stress increment ratio test; $\sigma_{1} / \sigma_{3}=$ constant means constant Kc test, which is also called constant stress ratio test. It can be seen from Figure 1 that the dilatancy points of sand under different stress paths are highly

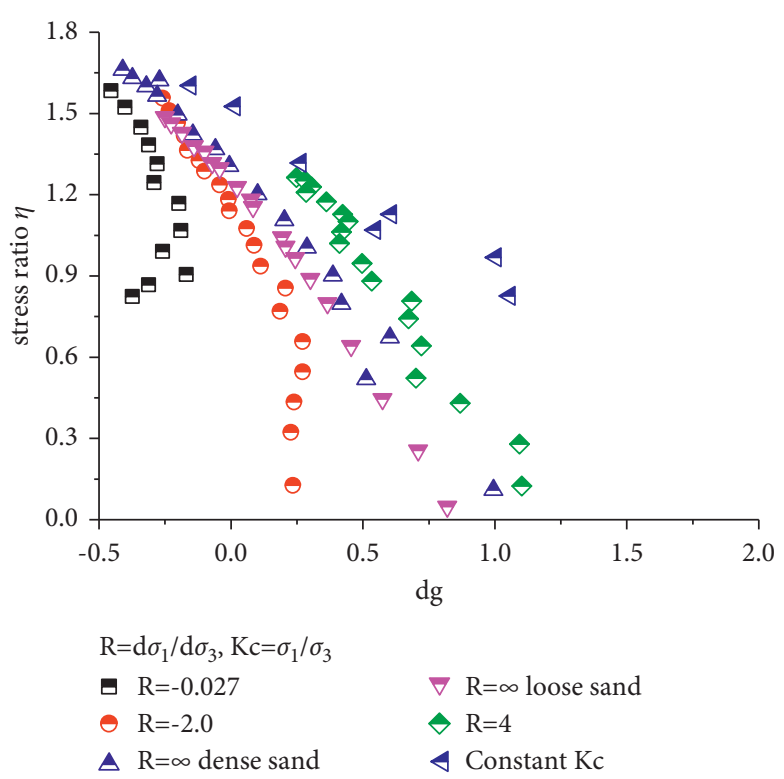

FIGURE 1: Stress-dilatancy of sand under different loading directions.

discrete, and it is difficult to describe them by unified dilatancy equation. For a single loading stress path, there is a good linear relationship between the dilatancy ratio $d g$ and the stress ratio $\eta$, but the different stress paths cannot be described by a unified curve. It can also be found that the dilatancy equation lines translate and rotate in one direction with different loading directions.

$\mathrm{Xu}$ et al. [26] carried out the triaxial loading test of the same rockfill with different stress paths, and the test results are rich. Based on the test data, the dilatancy equations of conventional triaxial, constant $\mathrm{P}$ loading and constant $\sigma 1$ loading tests are sorted out in Figure 2. Figure 3 summarizes the development law of dilatancy ratio with stress ratio in four loading directions [27] under confining pressure of $900 \mathrm{kPa}$. It can be seen that with the continuous change of stress loading direction, the dilatancy characteristics of rockfill materials under different loading modes show great differences. The dilatancy behavior of rockfill materials show obvious stress path dependence in the space of $d_{g}-\eta$, in which $d_{g}$ is dilatancy ratio and $\eta$ is stress ratio. It can be seen from Figures 1-3 that both rockfill materials and sand have similar stress path effect, and it is hard to describe the dilatancy characteristics of rockfill under various stress paths.

\subsection{Lade-Kim Method for Describing Dilatancy Equation.} Due to the difference of dilatancy equations under various stress paths and difficulty to give a unified form, a new method which can effectively describe the dilatancy equations under different stress paths is needed.

The single hardening model introduced by Lade and Kim [18-21] has predicted the behavior of sand, clay, and concrete under a variety of loading conditions. The true triaxial condition was taken into account in the establishment of the model, which has a strong applicability. Lade-Kim plastic potential may be a good choice to construct dilatancy equation incorporating stress path effect. 


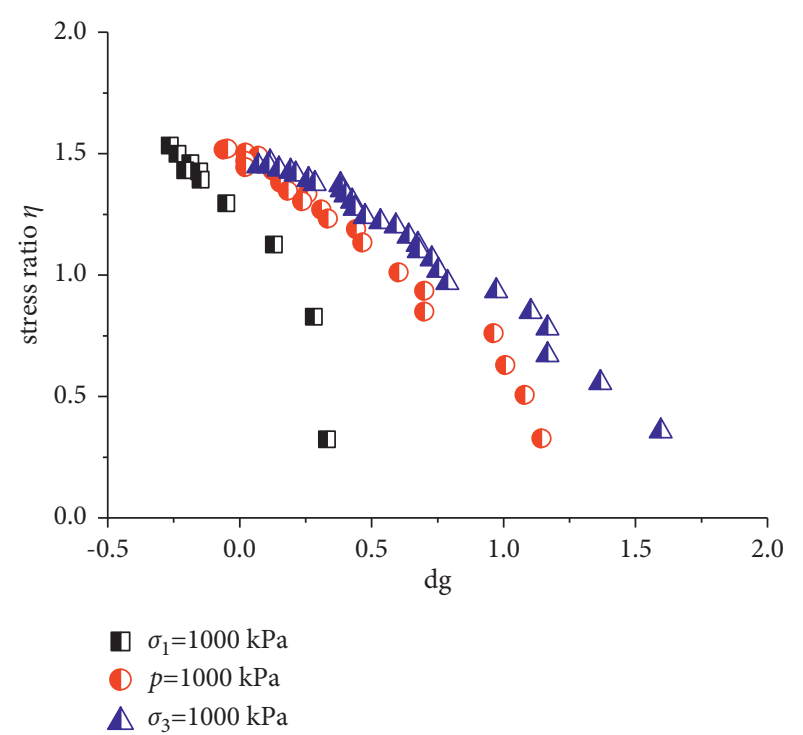

FIGURE 2: Stress-dilatancy of gravel along different loading paths.

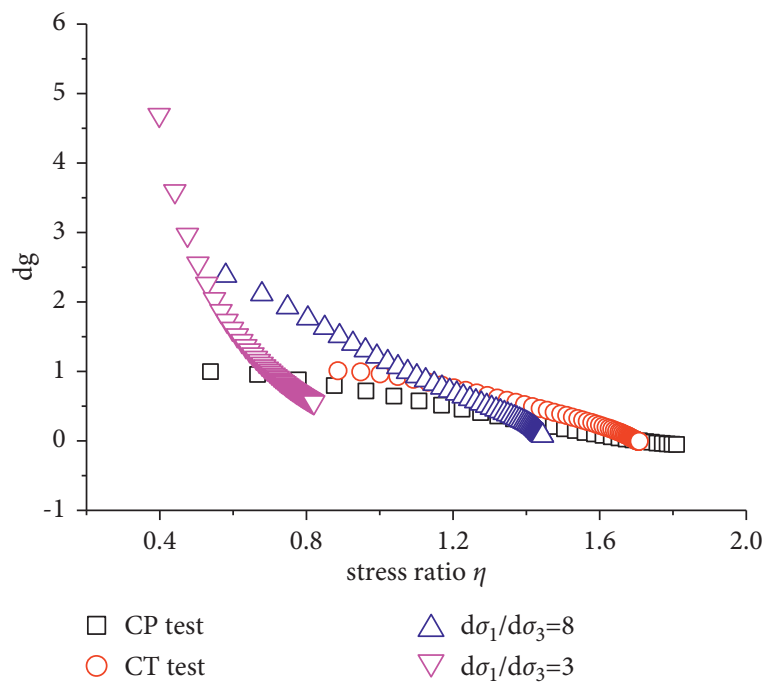

FIgURE 3: Stress-dilatancy of Yixing rockfill materials along different loading paths.

Lade and Kim [20] proposed a three-dimensional expression of plastic potential surface in principal stress space:

$$
G_{p}=\left[\psi_{1} \frac{I_{1}^{3}}{I_{3}}-\frac{I_{1}^{2}}{I_{2}}+\psi_{2}\right]\left[\frac{I_{1}}{p_{a}}\right]^{\mu} .
$$

In equation (1), $I_{1}, I_{2}$, and $I_{3}$ are the first, second, and third stress invariants; $\psi_{1}, \psi_{2}$, and $\mu$ are the model parameters; $p_{a}$ is the atmospheric pressure. The material parameters $\psi_{2}$ and $\mu$ are dimensionless constants that may be determined from triaxial compression tests. The parameter $\psi_{1}$ is related to the curvature parameter of the failure criterion as follows:

$$
\psi_{1}=0.00155 m^{-1.27},
$$

where $m$ is the strength parameter for geomaterials.

Two parameters $\eta_{1}$ and $m$ describing failure surface can be obtained by data fitting at failure point of conventional triaxial test. The failure surface form under normal triaxial state is as follows:

$$
\left[\frac{\left(\sigma_{1}+2 \sigma_{3}\right)^{3}}{\sigma_{1} \sigma_{3}^{2}}-27\right]\left(\frac{\sigma_{1}+2 \sigma_{3}}{p_{a}}\right)^{m}=\eta_{1} .
$$

By assuming that

$$
\begin{aligned}
& X=\frac{\sigma_{1}+2 \sigma_{3}}{p_{a}}, \\
& Y=\frac{\left(\sigma_{1}+2 \sigma_{3}\right)^{3}}{\sigma_{1} \sigma_{3}^{2}}-27 .
\end{aligned}
$$

Accordingly,

$$
Y=\eta_{1} X^{-m}
$$

Two strength parameters $\eta_{1}$ and $m$ are obtained by data collection and fitting on the $\mathrm{X}-\mathrm{Y}$ plane.

The invariant of the stress tensor in the formula can be expressed as follows:

$$
\begin{aligned}
& I_{1}=\sigma_{x}+\sigma_{y}+\sigma_{z}, \\
& I_{2}=\tau_{x y}^{2}+\tau_{y z}^{2}+\tau_{z x}^{2}-\left(\sigma_{x} \sigma_{y}+\sigma_{y} \sigma_{z}+\sigma_{z} \sigma_{x}\right), \\
& I_{3}=\sigma_{x} \sigma_{y} \sigma_{z}+2 \tau_{x y} \tau_{y z} \tau_{z x}-\left(\sigma_{x} \tau_{x y}^{2}+\sigma_{y} \tau_{y z}^{2}+\sigma_{z} \tau_{z x}^{2}\right) .
\end{aligned}
$$

In equations (6)-(8), $\sigma_{x}, \sigma_{y}, \sigma_{z}, \tau_{x y}, \tau_{y z}$, and $\tau_{z x}$ are stress variables for material element.

According to the theory of elastoplastic, the increment of plastic strain can be determined by the following formula:

$$
d \varepsilon_{i j}^{p}=d \lambda \frac{\partial G_{p}}{\partial \sigma_{i j}}
$$

where $d \lambda$ is the plastic multiplier and $\sigma_{i j}$ is the stress tensor.

Combining equation (1) with equations (6)-(8), it can be obtained that

$$
\begin{aligned}
\frac{\partial G}{\partial \sigma_{x}} & =\left[\frac{I_{1}}{p_{a}}\right]^{\mu}\left[G_{1}-\frac{\psi_{1} I_{1}^{3}}{I_{3}^{2}}\left(\sigma_{y} \sigma_{z}-\tau_{y z}^{2}\right)-\frac{I_{1}^{2}}{I_{2}^{2}}\left(\sigma_{z}+\sigma_{y}\right)\right], \\
\frac{\partial G}{\partial \sigma_{y}} & =\left[\frac{I_{1}}{p_{a}}\right]^{\mu}\left[G_{1}-\frac{\psi_{1} I_{1}^{3}}{I_{3}^{2}}\left(\sigma_{x} \sigma_{z}-\tau_{z x}^{2}\right)-\frac{I_{1}^{2}}{I_{2}^{2}}\left(\sigma_{x}+\sigma_{z}\right)\right], \\
\frac{\partial G}{\partial \sigma_{z}} & =\left[\frac{I_{1}}{p_{a}}\right]^{\mu}\left[G_{1}-\frac{\psi_{1} I_{1}^{3}}{I_{3}^{2}}\left(\sigma_{x} \sigma_{y}-\tau_{x y}^{2}\right)-\frac{I_{1}^{2}}{I_{2}^{2}}\left(\sigma_{x}+\sigma_{y}\right)\right], \\
\frac{\partial G}{\partial \tau_{x y}} & =\left[\frac{I_{1}}{p_{a}}\right]^{\mu}\left[2 \tau_{x y} \frac{I_{1}^{2}}{I_{2}^{2}}-2 \psi_{1} \frac{I_{1}^{3}}{I_{3}^{2}}\left(\tau_{y z} \tau_{z x}-\sigma_{z} \tau_{x y}\right)\right], \\
\frac{\partial G}{\partial \tau_{y z}} & =\left[\frac{I_{1}}{p_{a}}\right]^{\mu}\left[2 \tau_{y z} \frac{I_{1}^{2}}{I_{2}^{2}}-2 \psi_{1} \frac{I_{1}^{3}}{I_{3}^{2}}\left(\tau_{x y} \tau_{z x}-\sigma_{x} \tau_{y z}\right)\right], \\
\frac{\partial G}{\partial \tau_{z x}} & =\left[\frac{I_{1}}{p_{a}}\right]^{\mu}\left[2 \tau_{z x} \frac{I_{1}^{2}}{I_{2}^{2}}-2 \psi_{1} \frac{I_{1}^{3}}{I_{3}^{2}}\left(\tau_{x y} \tau_{y z}-\sigma_{y} \tau_{z x}\right)\right],
\end{aligned}
$$

where 


$$
G_{1}=\left[\psi_{1}(\mu+3) \frac{I_{1}^{2}}{I_{3}}-(\mu+2) \frac{I_{1}}{I_{2}}+\frac{\mu}{I_{1}} \psi_{2}\right]
$$

So, the dilatancy ratio $d_{g}$ of rockfill materials can be obtained as follows:

$$
d_{g}=\frac{d \varepsilon_{v}^{p}}{d \varepsilon_{s}^{p}}=\frac{\partial G_{p} / \partial \sigma_{m m}}{\sqrt{2} / 3\left(\partial G_{p} / \partial \sigma_{i j}-\partial G_{p} / \partial \sigma_{m m}\left(\delta_{i j} / 3\right)\left[\partial G_{p} / \partial \sigma_{i j}-\partial G_{p} / \partial \sigma_{m m}\left(\delta_{i j} / 3\right)\right]\right)}
$$

where $\varepsilon_{v}^{p}$ and $\varepsilon_{s}^{p}$ are the plastic volumetric strain and plastic deviatoric strain and $\delta_{i j}$ is the Kronecker delta.

It is worth noting that, for coarse-grained soil, particle breakage is an important factor. However, the measurement of particle breakage needs the grading curve before and after experiment, and the soil particle screening is a very timeconsuming and laborious work. Particle breakage data for the experiments involved in this paper are very limited. This paper mainly discussed Lade-Kim plastic potential applicability under various stress paths for rockfill materials, and the particle breakage effect is indirectly reflected in parameters of dilatancy equation. Thus, particle breakage was not considered in dilatancy equation.

Under the condition of triaxial compression $\left(\sigma_{2}=\sigma_{3}, \varepsilon_{2}=\varepsilon_{3}\right)$,

$$
\begin{aligned}
\frac{\partial G}{\partial \sigma_{1}} & =\left[\frac{I_{1}}{p_{a}}\right]^{\mu}\left[G_{1}-\frac{\psi_{1} I_{1}^{3}}{I_{3}^{2}} \sigma_{3}^{2}-2 \frac{I_{1}^{2}}{I_{2}^{2}} \sigma_{3}\right], \\
\frac{\partial G}{\partial \sigma_{2}} & =\frac{\partial G}{\partial \sigma_{3}}=\left[\frac{I_{1}}{p_{a}}\right]^{\mu}\left[G_{1}-\frac{\psi_{1} I_{1}^{3}}{I_{3}^{2}} \sigma_{1} \sigma_{3}-\frac{I_{1}^{2}}{I_{2}^{2}}\left(\sigma_{1}+\sigma_{3}\right)\right], \\
\chi & =\frac{d \varepsilon_{1}^{p}}{d \varepsilon_{3}^{p}}=\frac{\partial G / \partial \sigma_{1}}{\partial G / \partial \sigma_{3}},
\end{aligned}
$$

where $\varepsilon_{1}^{p}$ and $\varepsilon_{3}^{p}$ are the plastic axial strain and plastic radial strain and $\chi$ is the ratio of plastic axial strain increment to plastic radial strain increment.

The dilatancy stress ratio $d_{g}$ can be rewritten as

$$
d_{g}=\frac{d \varepsilon_{v}^{p}}{d \varepsilon_{s}^{p}}=\frac{d \varepsilon_{1}^{p}+2 d \varepsilon_{3}^{p}}{2 / 3\left(d \varepsilon_{1}^{p}-d \varepsilon_{3}^{p}\right)}=\frac{3 \chi+6}{2(\chi-1)} \text {. }
$$

2.3. Verification Method of Lade-Kim Dilatancy Equation. Lade-Kim's plastic potential dilatancy equation can be verified by triaxial test data, and the specific process method is as follows:

The incremental plastic strain ratio is first defined as

$$
v_{p}=-\frac{d \varepsilon_{3}^{p}}{d \varepsilon_{1}^{p}}
$$

Under the condition of triaxial compression, we can obtain equation (23) from equations (1), (9), and (13)-(14), that is,

$$
\xi_{y}=\frac{1}{\mu} \xi_{x}-\psi_{2}
$$

where

$$
\xi_{x}=\frac{1}{1+v_{p}}\left\{\frac{I_{1}^{3}}{I_{2}^{2}}\left(\sigma_{1}+\sigma_{3}+2 v_{p} \sigma_{3}\right)+\psi_{1} \frac{I_{1}^{4}}{I_{3}^{2}}\left(\sigma_{1} \sigma_{3}++2 v_{p} \sigma_{3}^{2}\right)\right\}-3 \psi_{1}\left(\frac{I_{1}^{3}}{I_{3}}+2 \frac{I_{1}^{2}}{I_{2}}\right)
$$

and

$$
\xi_{y}=\psi_{1} \frac{I_{1}^{3}}{I_{3}}-\frac{I_{1}^{2}}{I_{2}} .
$$

Equation (18) reveals the linear relationship between $\xi_{x}$ and $\xi_{y}$. Lade-Kim plastic potential applicability can be investigated by sorting out triaxial experimental data of $\xi_{x}$ and $\xi_{y}$ for rockfill materials. Correspondingly, Lade-Kim plastic potential surface can be used to characterize the dilatancy law of coarse-grained soil with different stress paths.

\section{Applicability Verification of Lade-Kim Dilatancy Equation under Different Stress Path Tests}

3.1. Conventional Triaxial Test. Lade-Kim's plastic potential surface is proposed based on a large number of sand and concrete tests. Since the plastic potential is established in three-dimensional stress space, it has certain adaptability to different stress paths, but it has not been verified for rockfill material tests. 
The conventional triaxial tests for three kinds of rockfill materials under different confining pressures are used to verify the applicability of Lade-Kim plastic potential, as shown in Figures 4-6. For the three types of rockfill tests, $\xi_{x}$ and $\xi_{y}$ show a good linear relationship, indicating that the plastic potential can better describe the dilatancy characteristics of conventional triaxial loading.

3.2. Constant $P$ Test. Constant $P$ triaxial compression test, e.g., increases the axial stress $\sigma 1$ and decreases the confining pressure $\sigma 3$ during loading, so as to keep the mean stress $\mathrm{P}$ unchanged. In three-dimensional space, the yield surface is still expanding, but the yield surface expansion is not obvious. By drawing the plastic potential curve, it can be seen that the $\xi_{x}-\xi_{y}$ curve still conforms to the linear relationship in Figures 7-9.

\subsection{Constant Stress Increment Ratio Test. Constant stress} increment ratio test, e.g., increases the axial stress $\sigma 1$ and small principal stress $\sigma 3$ during loading, so as to keep $\mathrm{d} \sigma 1 /$ $\mathrm{d} \sigma 3$ constant. In three-dimensional space, the yield surface expansion is obvious.

Figures 10 and 11 show the results of data arrangement at the same stress increment ratio. When the stress increment ratio is constant, the $\xi_{x}-\xi_{y}$ curve corresponding to each group of confining pressures is linear, but the slope and intercept of the curves are different. When the stress increment ratio is small, the difference of curve shape under different confining pressures is larger. It can be seen that both confining pressure and stress increment ratio have influence on the dilatancy characteristics of rockfill materials for constant stress increment ratio test, and a set of parameters cannot be used to describe the Lade-Kim dilatancy law.

3.4. Constant Stress Ratio Test. Constant stress ratio test, e.g., increases the axial stress $\sigma 1$ and small principal stress $\sigma 3$ during loading, so as to keep $R=\sigma 1 / \sigma 3$ constant. The value of initial confining pressure of this kind of tests is equal to 0 , and the stress ratio remains constant in the test. In threedimensional space, the yield surface expansion is obvious. By drawing $\xi y-\xi x$ curve, it can be seen from Figure 12 that a certain kind of experiments (such as $R=3.5$ ) has only one data point, and multiple groups of constant stress ratio loading test points still conform to the linear relationship.

\subsection{Comparison of Multiple Stress Path Tests}

3.5.1. Weakening Weathered Granite Rockfill Experiments [16] under Multiple Stress Paths. The $\xi y$ - $\xi x$ curve of various stress path tests of granite rockfill materials is exhibited in Figure 13. It is found that CT test and CP test have good consistency by sorting out $\xi y$ - $\xi x$ curves involved with LadeKim plastic potential, while data of three types of experiments (i.e., CT, CP, and CR tests) do not show linear relationship. Meanwhile, CR test under different stress ratios also has a good linear relationship for $\xi y$ - $\xi x$ curves.

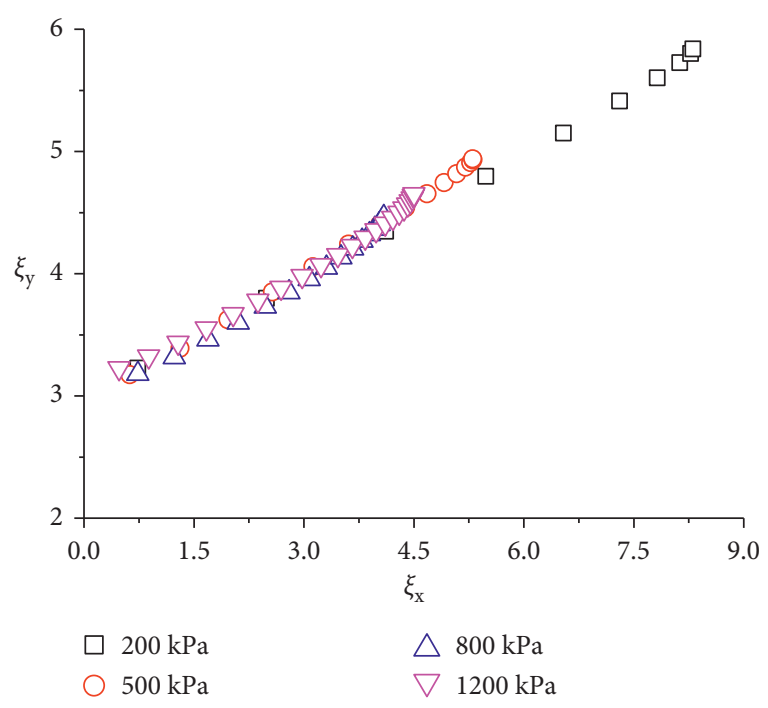

FIgURE 4: CT tests of Shuangjiangkou rockfill materials [11].

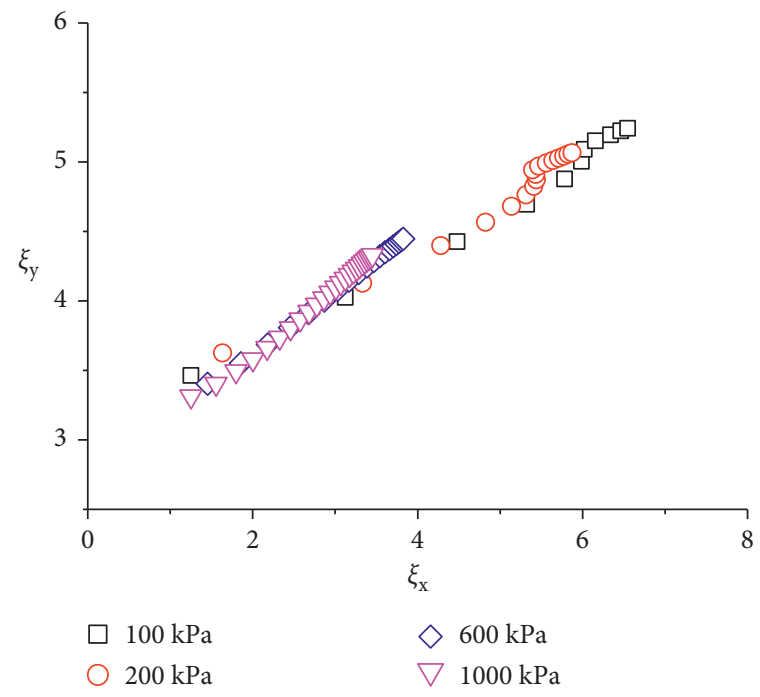

FIGURE 5: CT tests of limestone rockfill materials [26].

3.5.2. Liu's Tests. Yixing rockfill materials are from Yixing Pumped Storage Hydropower Station, located in Yixing, Jiangsu, China. For a variety of stress path tests of Yixing rockfill materials, by sorting out the Lade-Kim plastic potential related $\xi y-\xi x$ curves, it can be seen from Figure 14 that the data points of various tests are approximately linear. However, due to the concentration of $\mathrm{CIR}=3$ test data points, the curve obtained after reducing the scale range of coordinate axis is shown in Figure 11. It can be seen from Figure 11 that the $\xi y-\xi x$ curves of $\mathrm{CIR}=3$ test have a large deviation from other tests.

The stress loading path direction is defined as follows:

$$
\beta=\tanh \left(\frac{d p}{d q}\right),
$$

where $p$ is the mean stress, which equals $(\sigma 1+\sigma 2+\sigma 3) / 3$, and $q$ is the deviatoric stress that equals $(\sigma 1-\sigma 3)$.

By analyzing the triaxial tests of granite rockfill and Yixing rockfill under various stress paths, it is found that 


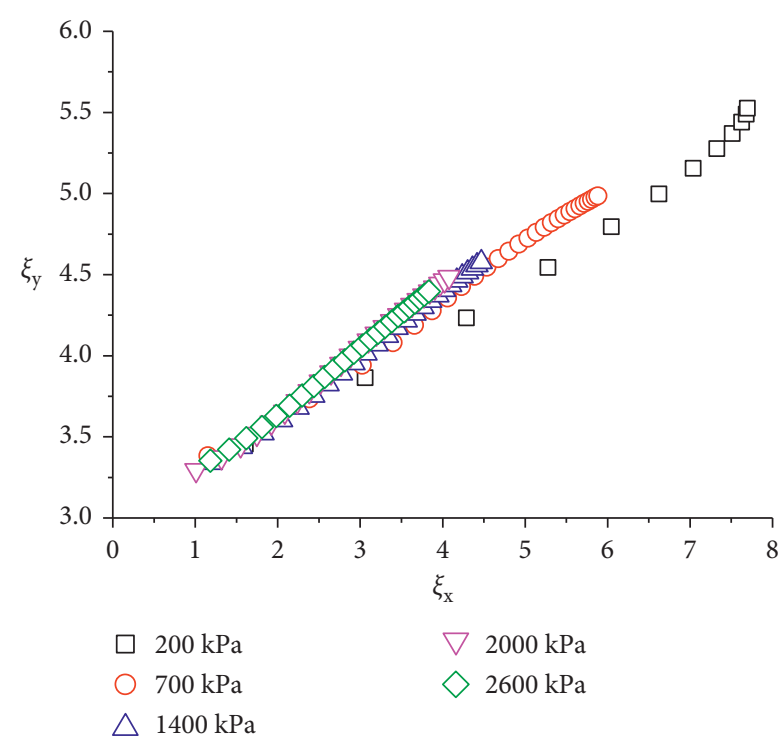

Figure 6: Conventional triaxial test of granite rockfills [16].

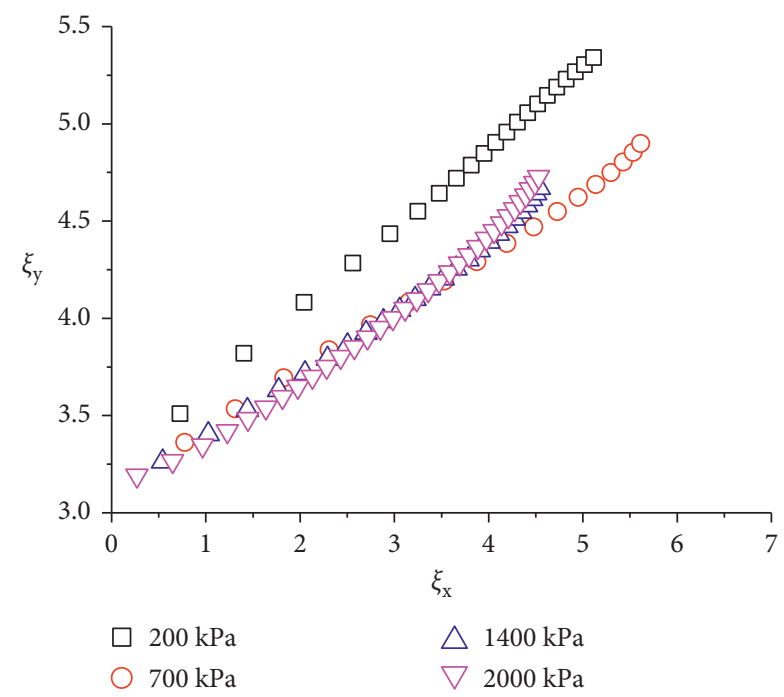

Figure 7: CP tests of granite rockfills [16].

Lade-Kim plastic potential data points $\xi y$ and $\xi x$ have a certain linear relationship under the condition of $\beta$ less than 0.3215 or nearby, and the data points for $\xi y$ and $\xi x$ greater than 0.3215 have greater dispersion. That is to say, Lade-Kim plastic potential is suitable for the case where the loading parameter $\beta$ is less than 0.3215 or near the value of 0.3215 , and it has consistency. When $\beta$ is greater than 0.3215 , the selection of plastic potential parameters should be particularly careful.

\section{Application of Lade-Kim Plastic Potential in Elastoplastic Model}

The generalized plasticity model was first proposed by Pastor et al. [28] to establish a unified static and dynamic constitutive model. In the generalized plasticity model, flow direction, loading direction, and plastic modulus are explicitly defined. The model is simple and convenient to be embedded

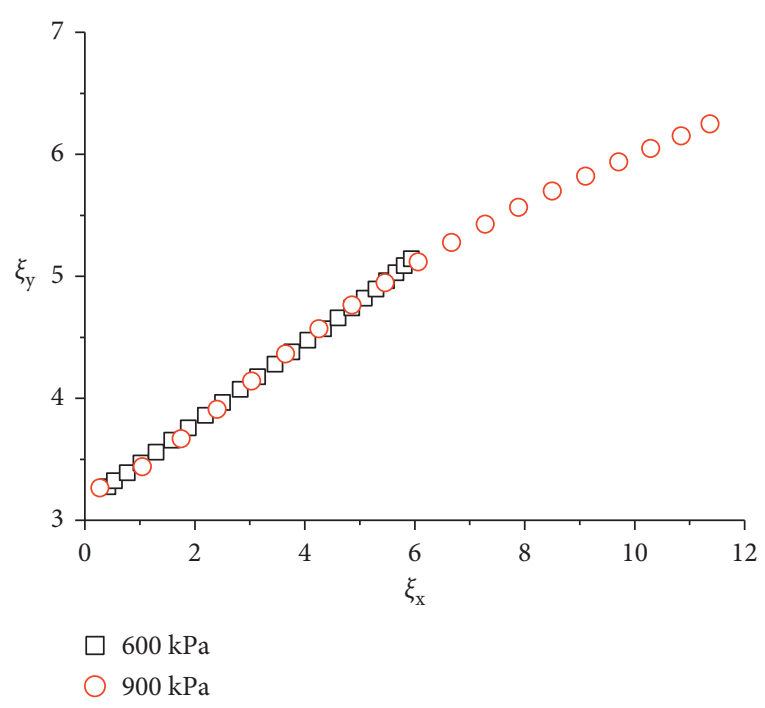

FIGURE 8: CP tests of Yixing rockfill materials [27].

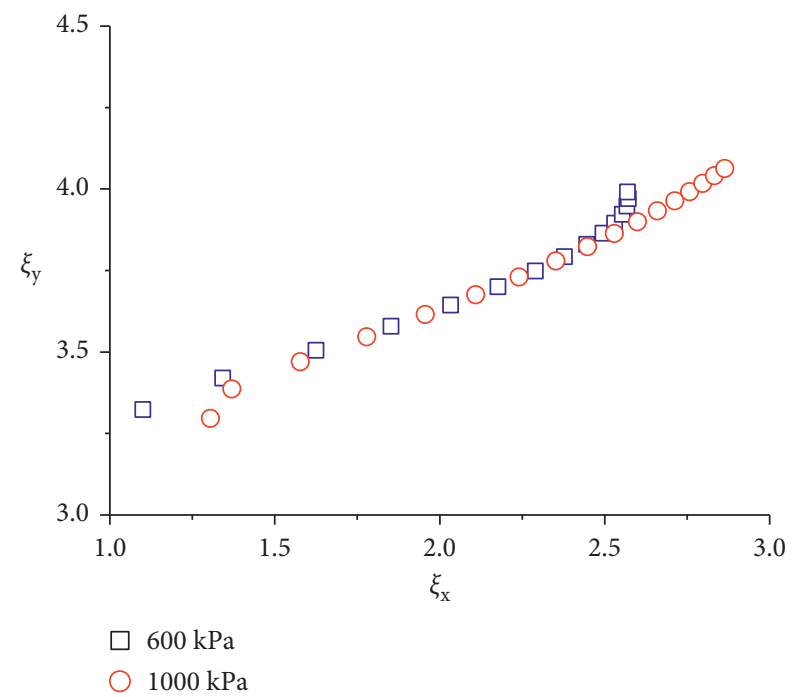

FIGURE 9: CT tests of limestone rockfill materials [27].

in program. Since the Lade-Kim dilatancy equation can be deduced from the Lade-Kim plastic potential, the Lade-Kim plastic potential can be evaluated by changing the dilatancy equation in the framework of generalized plasticity. The Lade-Kim dilatancy equation and nonlinear dilatancy equation are two dilatancy equations to be evaluated.

4.1. Elastoplastic Stiffness Matrix. In the elastoplastic model, the increment of stress and strain has the following relationship:

$$
d \sigma=D^{e p} d \varepsilon
$$

The elastoplastic stiffness matrix $D_{e p}$ in the generalized plasticity model is defined as follows:

$$
\mathbf{D}^{e p}=\mathbf{D}^{e}-\frac{\left(\mathbf{D}^{e}: \mathbf{n}_{g}\right) \otimes\left(\mathbf{n}_{f}: \mathbf{D}^{e}\right)}{H+\mathbf{n}_{f}: \mathbf{D}^{e}: \mathbf{n}_{g}},
$$




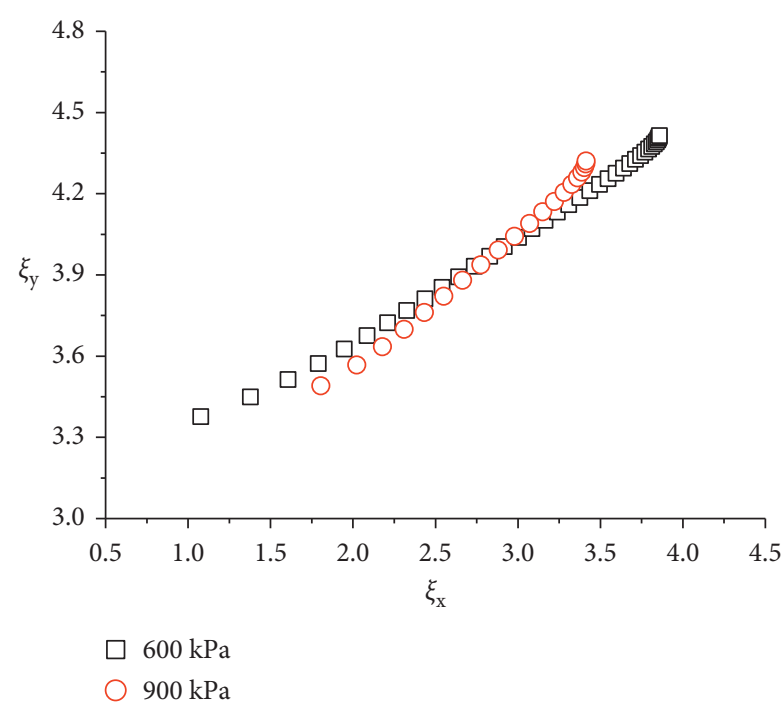

Figure 10: CIR test of limestone rockfill materials [27] (d $\sigma 1 /$ $\mathrm{d} \sigma 3=8)$.

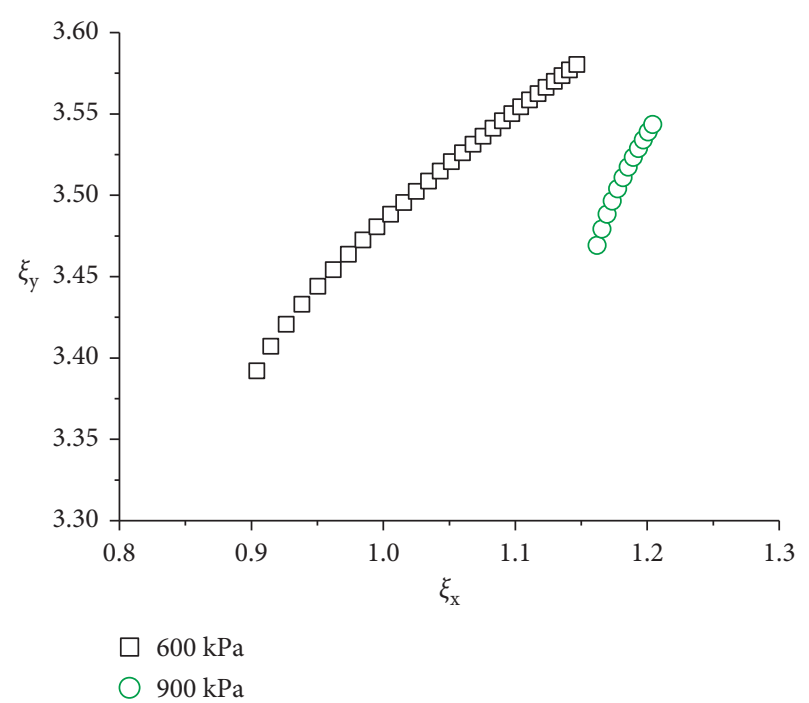

FIGURE 11: CIR test of limestone rockfill materials [27] (d $\sigma 1 /$ $\mathrm{d} \sigma 3=3)$.

where $\mathbf{n}_{g}$ is the plastic potential flow direction; $\mathbf{n}_{f}$ is the loading direction; $H$ is the loading and unloading plastic modulus; $\mathbf{D}^{e}$ is the elastic matrix; and $\mathbf{D}^{e p}$ is the elastoplastic matrix. The flow direction, loading direction, and plastic modulus are important components of generalized plasticity model.

\subsection{Flow Direction and Loading Direction}

4.2.1. Plastic Flow Direction. The explicit expression of the plastic flow direction can be expressed as follows:

$$
\mathbf{n}_{g}=\frac{1 / 3 d_{g} \delta_{i j}+3 s_{i j} / 2 q}{\sqrt{1 / 3 d_{g}^{2}+3 / 2}},
$$

in which

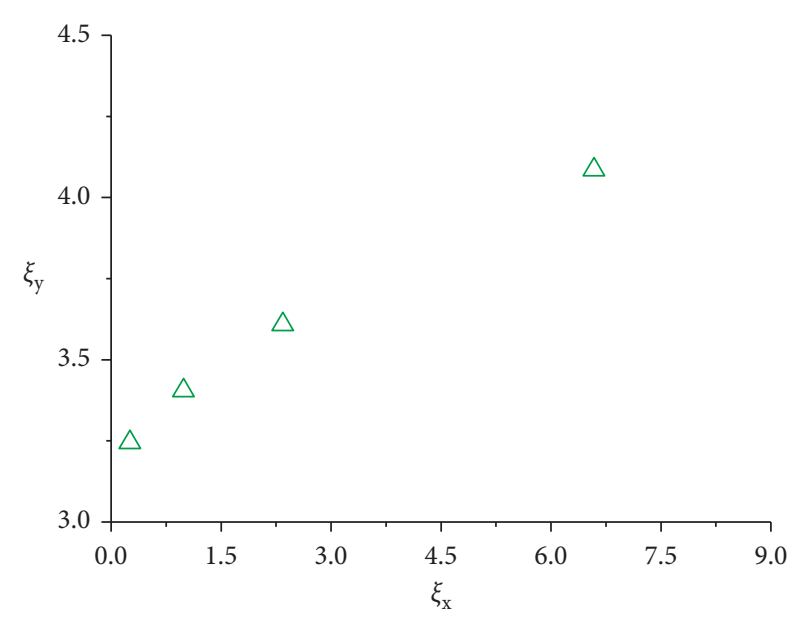

$\triangle$ Constant stress ratio test

FIGURE 12: CR test of granite rockfill materials [16] $(\sigma 1 / \sigma 3=1.5,2.0$, 2.5, and 3.5)

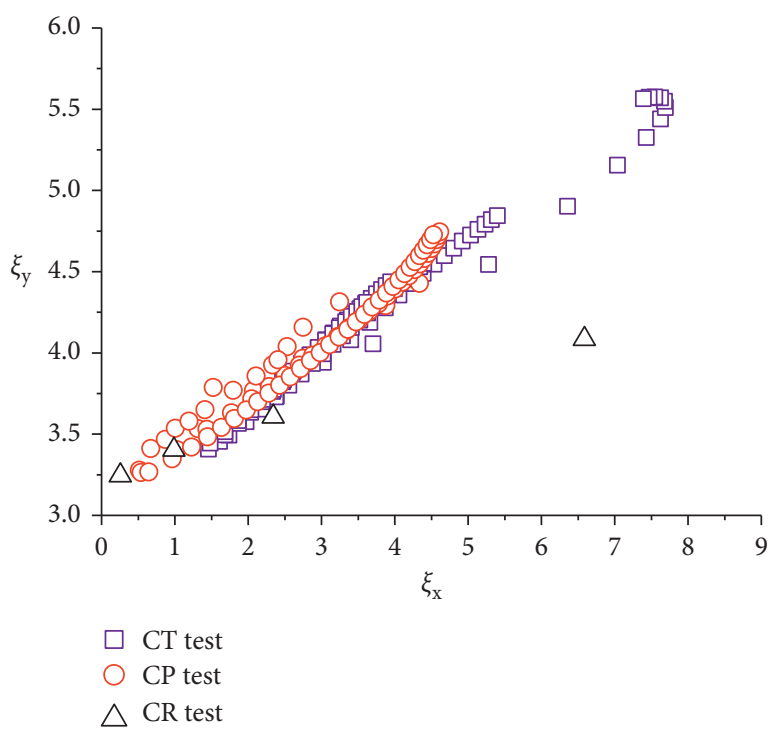

FIGURE 13: Various stress path tests of granite rockfill materials [16].

$$
\begin{aligned}
d_{g} & =\frac{d \varepsilon_{v}^{p}}{d \varepsilon_{s}^{p}}, \\
q & =\sqrt{\frac{3}{2} s_{i j} s_{i j}} .
\end{aligned}
$$

The Lade-Kim dilatancy equation is equation (12) and the nonlinear dilatancy equation, similar to the one proposed by $\mathrm{Fu}$ et al. [24], is listed as follows:

$$
d g=d_{g 0}\left[1-\left(\frac{\eta}{M_{c}}\right)^{\gamma}\right]
$$

where $d_{g 0}$ and $\gamma$ are the dilatancy parameters; $\eta$ is the stress ratio; and $M_{c}$ is the dilatancy stress ratio.

4.2.2. Loading Direction. The loading direction tensor is similar to the plastic direction tensor, that is, 


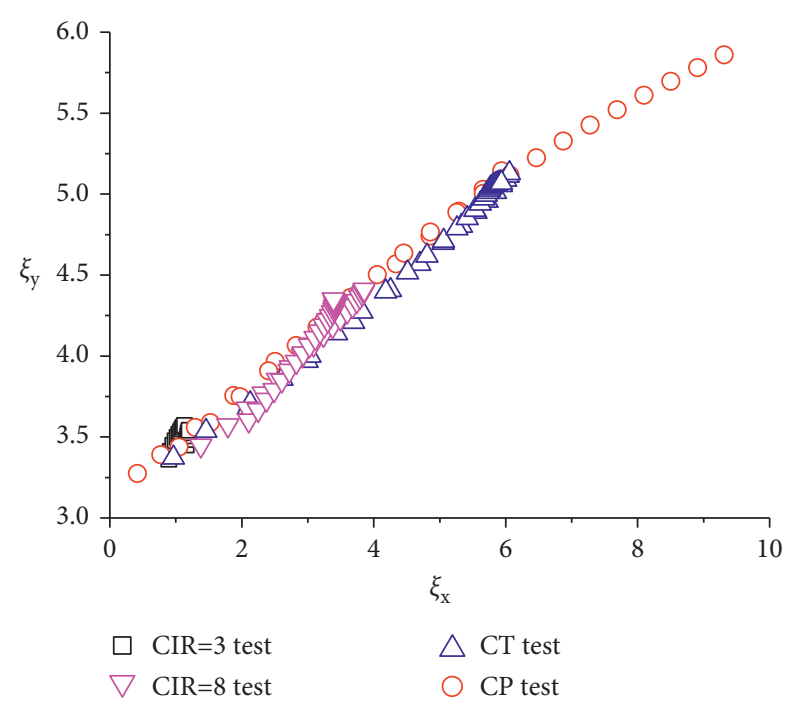

FIGURE 14: Various stress path tests of Yixing rockfill materials [27].

$$
\begin{aligned}
& \mathbf{n}_{f}=\frac{1 / 3 d_{f} \delta_{i j}+3 s_{i j} / 2 q}{\sqrt{1 / 3 d_{f}^{2}+3 / 2}}, \\
& d_{f}=M_{f}-\eta .
\end{aligned}
$$

A nonlinear expression [24] is used to describe the peak stress ratio:

$$
M_{f}=M_{f 0}\left(\frac{p}{p_{a}}\right)^{-n_{0}},
$$

where $M_{f 0}$ and $n_{0}$ are the strength parameters and the peak stress ratio is the function of $p$.

4.3. Plastic Modulus and Elastic Modulus. Fu et al. [29] studied the mechanical properties of rockfill under cyclic loading and deduced an explicit plastic modulus. According to the plastic strain increment relationship,

$$
d \boldsymbol{\varepsilon}^{p}=\frac{\mathbf{n}_{f}: d \boldsymbol{\sigma}}{H} \mathbf{n}_{g} .
$$

Further considering the elastic deformation, for the triaxial compression test under different stress paths, it can be obtained that

$$
\begin{aligned}
& \left(\begin{array}{c}
d \varepsilon_{1} \\
d \varepsilon_{2} \\
d \varepsilon_{3}
\end{array}\right)=\frac{1}{E_{e}}\left[\begin{array}{ccc}
1 & -v & -v \\
-v & 1 & -v \\
-v & -v & 1
\end{array}\right]\left(\begin{array}{c}
d \sigma_{1} \\
d \sigma_{2} \\
d \sigma_{3}
\end{array}\right)+\frac{1}{H} \frac{1}{3\left\|n_{g}\right\|}\left(\begin{array}{c}
d_{g}+3 \\
d_{g}-\frac{3}{2} \\
d_{g}-\frac{3}{2}
\end{array}\right) \frac{1}{3\left\|n_{f}\right\|}\left(\begin{array}{c}
d_{f}+3 \\
d_{f}-\frac{3}{2} \\
d_{f}-\frac{3}{2}
\end{array}\right)^{T}\left(\begin{array}{c}
d \sigma_{1} \\
d \sigma_{2} \\
d \sigma_{3}
\end{array}\right), \\
& \left\|\mathbf{n}_{g}\right\|=\sqrt{\frac{1}{3} d_{g}^{2}+\frac{3}{2}}, \\
& \left\|\mathbf{n}_{f}\right\|=\sqrt{\frac{1}{3} d_{f}^{2}+\frac{3}{2}} \text {. } \\
& E_{t}^{*}=\frac{d q}{d \varepsilon_{1}}=\frac{d\left(\sigma_{1}-\sigma_{3}\right)}{d \varepsilon_{1}}, \\
& E_{t}=\frac{d \sigma_{1}}{d \varepsilon_{1}} \\
& E_{t}^{*}=\left(1-\frac{\eta}{M_{f}}\right)^{\alpha} \cdot k_{t} \cdot p_{a} \cdot\left(\frac{\sigma_{c}}{p_{a}}\right)^{n},
\end{aligned}
$$

where $E_{e}$ and $v$ are the elastic modulus and Poisson's ratio.

The norm of the plastic flow direction tensor and that of the loading direction tensor are given as follows:

For triaxial compression state $\sigma_{1}>\sigma_{2}=\sigma_{3}$, the tangent modulus $E_{t}^{*}$ and conventional tangent modulus $E_{t}$ are defined as follows:
Under triaxial loading condition $d \sigma_{1}>0, R_{\Delta}=d \sigma_{3} /$ $d \sigma_{1}\left(R_{\Delta}<1\right)$,

$$
E_{t}=\frac{E_{t}^{*}}{1-R_{\Delta}} .
$$


TABLE 1: Model parameters.

\begin{tabular}{lccccccccccccc}
\hline & \multicolumn{4}{c}{ Model parameters (excluding dilatancy) } & \multicolumn{4}{c}{ Lade-Kim dilatancy } & \multicolumn{3}{c}{ Nonlinear dilatancy } \\
Exp. & $k_{a u}$ & $n$ & $v$ & $k_{t}$ & $\alpha$ & $M_{f 0}$ & $n_{0}$ & $\psi_{1}$ & $\psi_{2}$ & $\mu$ & $d_{g 0}$ & $M_{c}$ & $\gamma$ \\
\hline CT & 1440 & 0.5 & 0.2 & 200 & 0.8 & 2.02 & 0.1 & 0.0059 & -2.62 & 2.04 & 1.2 & 1.50 & 4.0 \\
CP & 1440 & 0.5 & 0.2 & 370 & 0.8 & 2.02 & 0.1 & 0.0059 & -2.72 & 2.18 & 0.84 & 1.46 & 4.0 \\
CR & 1380 & 0.34 & 0.3 & 500 & 2.3 & 2.34 & 0.132 & 0.0091 & -1.51 & 0.57 & 1.9 & 0.84 & 3.0 \\
\hline
\end{tabular}

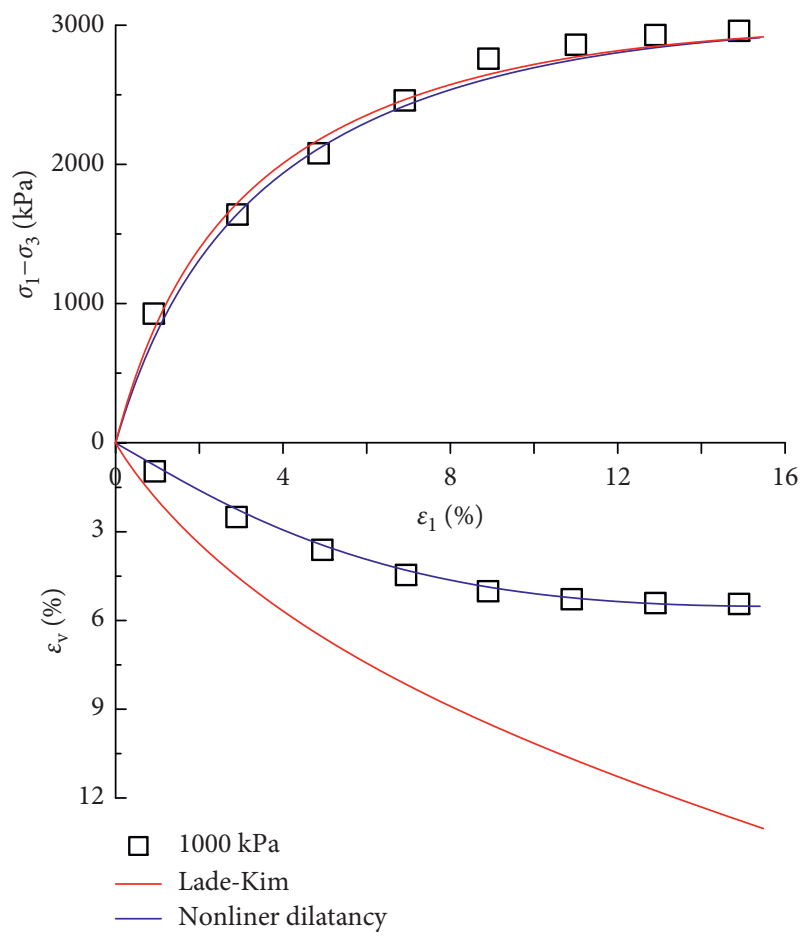

Figure 15: Model prediction results for CT experiments.

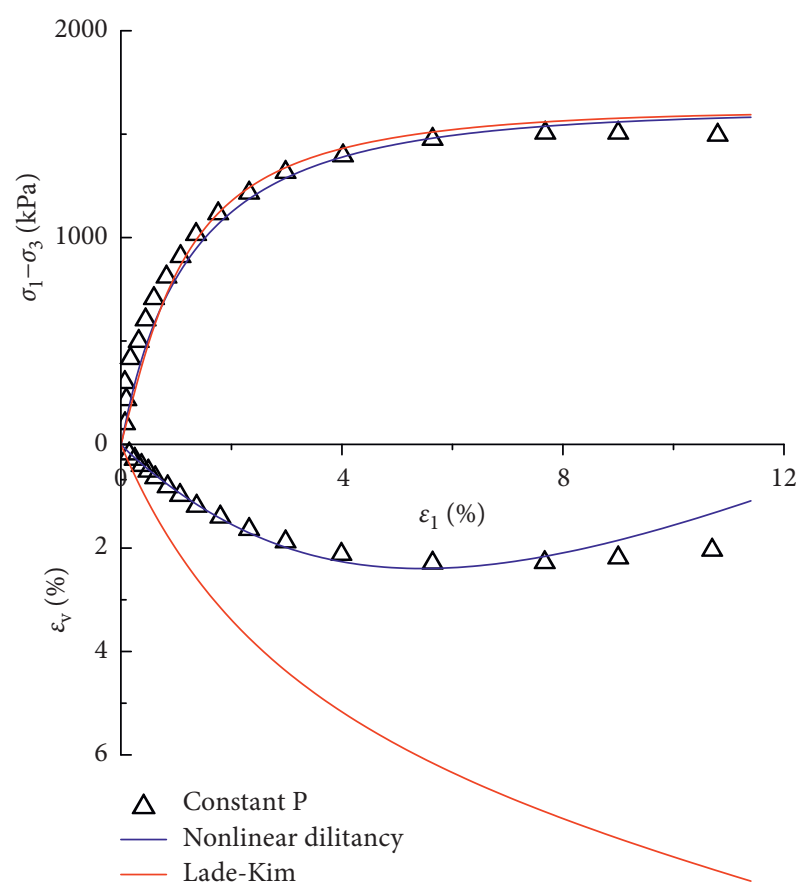

FIgURE 16: Model prediction results for CP experiments.

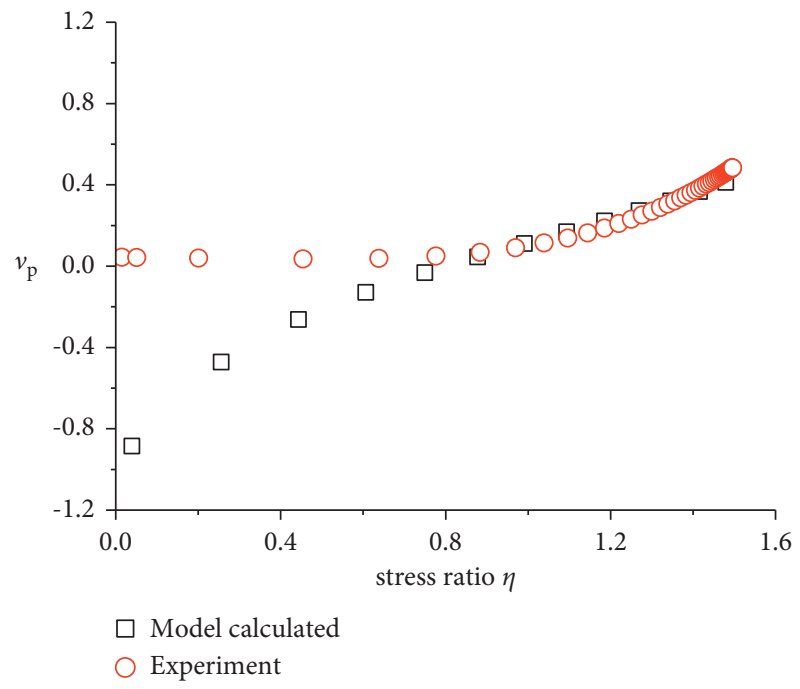

FIgURE 17: The evolution of $v_{p}$ for CT experiments.

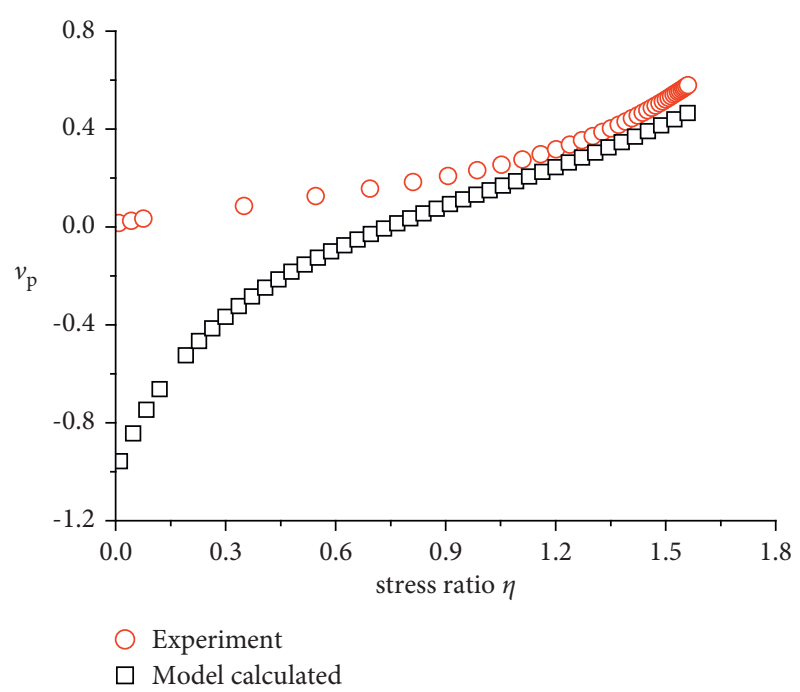

FIgURE 18: The evolution of $v_{p}$ for CP experiments.

The plastic modulus can be derived, that is,

$$
H=\frac{\left(d_{g}+3\right)\left[\left(1+2 R_{\Delta}\right) d_{f}+3-3 R_{\Delta}\right]}{9\left[1 / E_{t}-1 / E_{e}\left(1-2 v R_{\Delta}\right)\right] \sqrt{1 / 3 d_{g}^{2}+3 / 2} \sqrt{1 / 3 d_{f}^{2}+3 / 2}}
$$

It is assumed that the elastic modulus is consistent under various stress paths: 


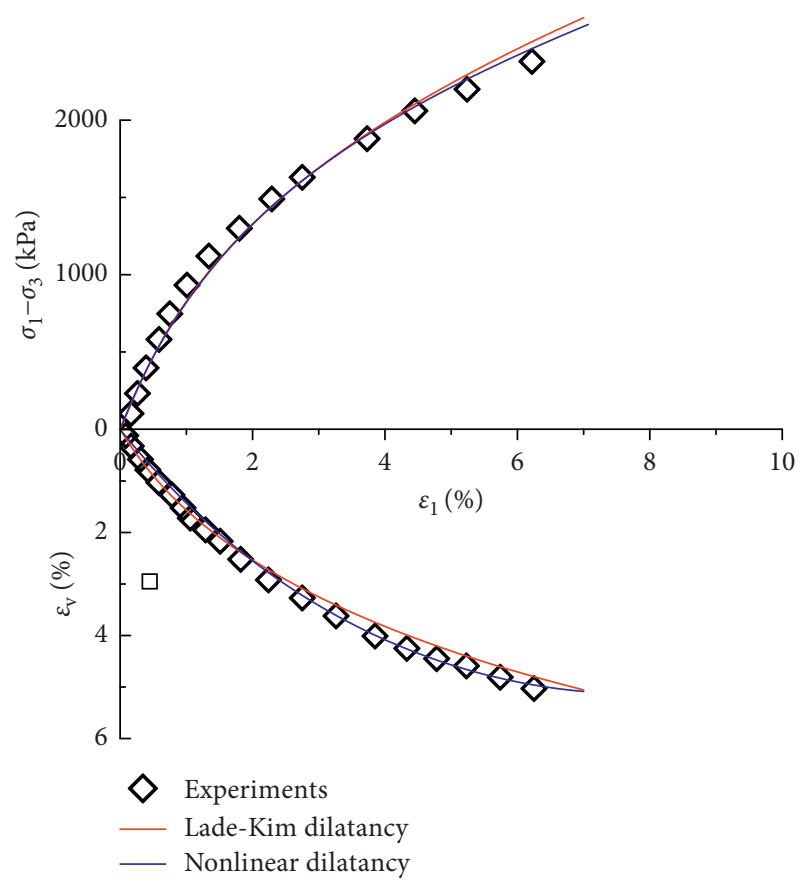

Figure 19: Model prediction results for constant stress increment ratio experiments.

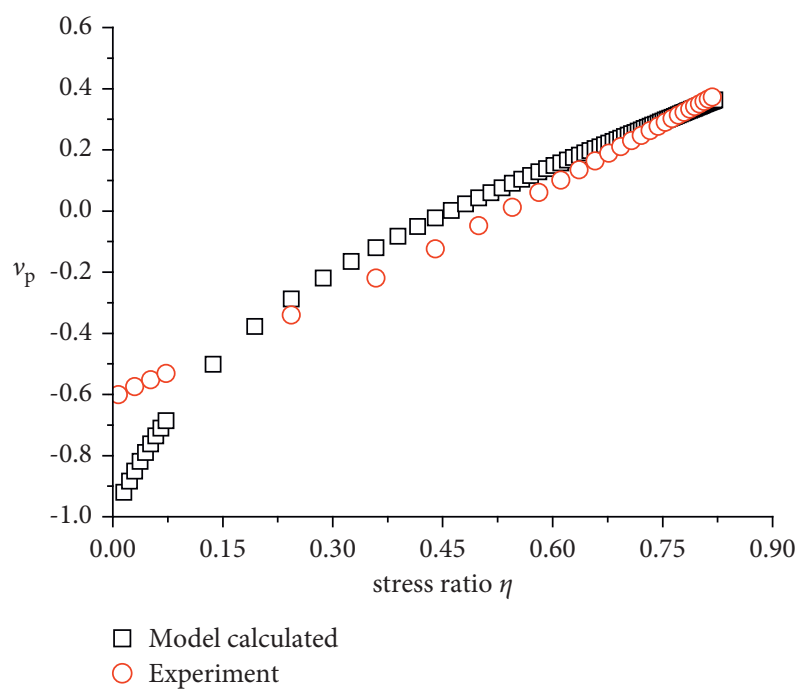

FIGURE 20: The evolution of $v_{p}$ for constant stress increment ratio experiments.

$$
\begin{aligned}
E_{e} & =k_{a u} p_{a}\left(\frac{p}{p_{a}}\right)^{n}, \\
G_{e} & =\frac{E_{e}}{2(1+v)}, \\
K_{e} & =\frac{E_{e}}{3(1-2 v)},
\end{aligned}
$$

where $k_{a u}$ is the elastic modulus parameter and $G_{e}$ and $K_{e}$ are the shear modulus and bulk modulus.
4.4. Model Validation and Analysis. In this paper, the applicability of Lade-Kim plastic potential for triaxial tests of rockfill materials is evaluated by using two kinds of dilatancy equations to predict CT, CP, and constant stress increment ratio tests in the framework of generalized plasticity.

The three typical tests verified here include conventional triaxial test under $1000 \mathrm{kPa}$ confining pressure, constant $\mathrm{P}$ test under $1000 \mathrm{kPa}$ confining pressure, and constant stress increment ratio test under $900 \mathrm{kPa}$ confining pressure ( $\mathrm{d} \sigma 1 /$ $\mathrm{d} \sigma 3=3)$. The Lade-Kim plastic potential parameters are obtained by sorting out $\xi y-\xi x$ curves. The parameters of the nonlinear dilatancy equation are obtained by arranging dg- $\eta$ curves. The calibration methods of other model parameters are shown in the literature [24]. The parameters of generalized plasticity models using two kinds of dilatancy equations are listed in Table 1.

It can be seen from the three types of test prediction curves in Figures 15 and 16 that the nonlinear dilatancy equation is suitable for describing the dilatancy characteristics of rockfill materials under different stress paths. When Lade-Kim plastic potential is applied to conventional triaxial and constant $\mathrm{P}$ tests, it seems that there are some deviations. The reason for this deviation is that $\nu \mathrm{p}$ obtained from the experimental data is quite different from the $v \mathrm{p}$ calculated by the model. It can be seen from Figures 17 and 18 that, for Lade-Kim plastic potential, the value of $\nu \mathrm{p}$ is equal to 1 at the beginning of loading and then gradually transits to a constant value. But in the actual test, the initial value of $\nu \mathrm{p}$ is not equal to 1 , even a positive value, and then transition to a fixed value. In order to make LadeKim's plastic potential suitable for conventional triaxial and constant $\mathrm{P}$ tests, it is necessary to ensure that the initial $\nu \mathrm{p}$ value of the test approaches to 1 . As can be seen from Figure 19, the Lade-Kim plastic potential and the nonlinear dilatancy equation show the similar prediction results for the constant stress increment ratio test. Figure 20 presents the evolution of $v \mathrm{p}$ for constant stress increment ratio experiments. The main reason for similar prediction results is that the $\nu$ p obtained from the test data is close to the value calculated by the model, although there are some deviations in the initial stage of loading. In conclusion, for the triaxial test of rockfill materials, Lade-Kim plastic potential is more suitable for constant stress increment ratio loading, and there is a certain deviation for other stress paths, such as conventional triaxial and constant $\mathrm{P}$ stress paths. We need to be especially careful when Lade-Kim plastic potential is applied into conventional triaxial and constant $\mathrm{P}$ stress paths.

\section{Conclusion}

In this paper, based on a large number of coarse-grained material stress path tests, the adaptability of Lade-Kim plastic potential equation for different stress paths is evaluated and analyzed. The Lade-Kim plastic potential, together with nonlinear dilatancy equation, is applied in elastoplastic model to model the behavior of rockfill materials under various stress paths. The main conclusions are as follows: 
(1) The dilatancy characteristics of coarse-grained materials are different under different loading stress paths. The parameters for Lade-Kim plastic potential equation were calibrated only by a single soil triaxial compression test which may be not enough. It is necessary to calibrate Lade-Kim plastic potential parameters by multiple stress path tests.

(2) Lade-Kim plastic potential has good applicability to single stress path, such as conventional triaxial test, constant $\mathrm{P}$ test, constant stress ratio test, and constant stress increment ratio test, but it is difficult to consider the influence of stress paths on original Lade-Kim plastic potential for the same geotechnical materials. The plastic potential parameters $\psi 1$ and $\psi 2$ are not obviously affected by the stress path, but the parameter $\mu$ is significantly affected by the loading stress path.

(3) The Lade-Kim plastic potential and nonlinear dilatancy equation present different prediction results, when applied to the generalized plasticity model. Lade-Kim plastic potential is more suitable for constant stress increment ratio loading experiments and special care should be taken when applied to other stress paths. When the Lade-Kim plastic potential is applied to the triaxial test of rockfill materials, it needs to be further modified so that the stress path dependency can be considered.

\section{Data Availability}

All data and models generated or used during this study appear in the published article.

\section{Conflicts of Interest}

The authors declare that they have no conflicts of interest.

\section{Acknowledgments}

The work presented in this paper was supported by Open Research Fund of Key Laboratory of Failure Mechanism and Safety Control Techniques of Earth-Rock Dam of the Ministry of Water Resources, Open Research Fund of Key Laboratory of Ministry of Education for Geomechanics and Embankment Engineering, Hohai University, No.2020003, Major Special Project of Ningbo Transportation Science and Technology (No. 202018), and Science and Technology Program of Zhejiang Provincial Communications Department (No. 2019040). These financial supports are gratefully acknowledged.

\section{References}

[1] P. W. Rowe, "The stress-dilatancy relation for static equilibrium of an assembly of particles in contact," Proceedings of the Royal Society of London A: Mathematical, Physical and Engineering Sciences, The Royal Society, London, UK, 1962.

[2] R. Nova and D. M. Wood, "A constitutive model for sand in triaxial compression," International Journal for Numerical and Analytical Methods in Geomechanics, vol. 3, no. 3, pp. 255-278, 1979.

[3] M. Jefferies, "Plastic work and isotropic softening in unloading," Géotechnique, vol. 47, no. 5, pp. 1037-1042, 1997.

[4] B.-Y. Zhang, Y.-A. Jia, and Z.-L. Zhang, "Modified Rowe's dilatancy law of rockfill and Shen Zhujiang's double yield surfaces elastoplastic model," Chinese Journal of Geotechnical Engineering, vol. 29, no. 10, pp. 1443-1448, 2007.

[5] Z.-J. Wang, S. S. Chen, and Z.-Z. Fu, "Dilatancy behaviors and generalized plasticity constitutive model of rockfill materials," Rock and Soil Mechanics, vol. 36, no. 7, pp. 1931-1938, 2015, in Chinese.

[6] Y.-F. Jia, S. C. Chi, and G. Lin, "Dilatancy unified constitutive model for coarse granular aggregates incorporating particle breakage," Rock and Soil Mechanics, vol. 31, no. 5, pp. 1383-1388, 2010, in Chinese.

[7] Z.-L. Cheng, H.-S. Ding, and L. P. Wu, "Experimental study on mechanical behaviour of granular material[J]," Chinese Journal of Geotechnical Engineering, vol. 29, no. 8, pp. 1151-1158, 2007, in Chinese.

[8] J.-M. Liu, Elasto-plastic Constitutive Models of Rockfill Material and Soil-Structure Interface and Their Applications on concrete-faced Rockfili dam, Dalian University of Technology, Dalian, China, 2015, in Chinese.

[9] W. Hu, Z. Yin, C. Dano, and P.-Y. Hicher, "A constitutive model for granular materials considering grain breakage," Science China Technological Sciences, vol. 54, no. 8, pp. 2188-2196, 2011.

[10] Y. Jia, B. Xu, S. Chi, and B. Xiang, "Particle breakage of rockfill material during triaxial tests under complex stress paths," International Journal of Geomechanics, vol. 19, no. 12, pp. 04019124.1-04019124.13, 2019.

[11] W. L. Guo and J. G. Zhu, "Energy consumption of particle breakage and stress dilatancy in drained shear of rockfill materials," Géotechnique Letters, vol. 7, no. 4, pp. 1-20, 2017.

[12] H.-L. Liu, D.-A. Sun, and Y. Shen, "Shear behavior of coarse aggregates for dam construction under varied stress paths," Water Science and Engineering, vol. 1, no. 1, pp. 63-77, 2008.

[13] M.-C. Liu, Y.-F. Gao, and H.-L. Liu, "Study on shear behaviors of rockfill in large-scale triaxial tests under different stress paths," Chinese Journal of Rock Mechanics and Engineering, vol. 27, no. 1, pp. 176-186, 2008, in Chinese.

[14] Z.-L. Zhang, Y.-A. Jia, and B.-Y. Zhang, "Comparison and verification of constitutive models for rockfill materials under complex stress path," Rock and Soil Mechanics, vol. 29, no. 5, pp. 1147-1151, 2008, in Chinese.

[15] X.-W. Gu, R. Shen, and Y.-Q. Zhang, "Study on stress-strain properties of rockfill materials under different stress paths in Nuzhadu project," Chinese Journal of Rock Mechanics and Engineering, vol. 27, pp. 3251-3260, 2008, in Chinese.

[16] G. Yang, X. Sun, Y.-Z. Yu, and B.-Y. Zhang, "Experimental study of mechanical behavior of a coarse- grained material under various stress paths," Rock and Soil Mechanics, vol. 31, no. 4, pp. 1118-1122, 2008, in Chinese.

[17] J.-F. Chen, M. Xu, E.-X. Song, and B. X. Cao, "Large scale triaxial testing on mechanical properties of broken limestone under various stress paths," Engineering Mechanics, vol. 29, no. 8, pp. 195-201, 2012, in Chinese.

[18] P. V. Lade and M. K. Kim, "Single hardening constitutive model for soil, rock and concrete," International Journal of Solids and Structures, vol. 32, no. 14, pp. 1963-1978, 1995.

[19] M. K. Kim and P. V. Lade, "Single hardening constitutive model for frictional materials," Computers and Geotechnics, vol. 5, no. 4, pp. 307-324, 1988. 
[20] P. V. Lade and M. K. Kim, "Single hardening constitutive model for frictional materials II. Yield critirion and plastic work contours," Computers and Geotechnics, vol. 6, no. 1, pp. 13-29, 1988.

[21] P. V. Lade and M. K. Kim, "Single hardening constitutive model for frictional materials III. Comparisons with experimental data," Computers and Geotechnics, vol. 6, no. 1, pp. 31-47, 1988.

[22] K.-M. Wei and S. Zhu, "A generalized plasticity model to predict behaviors of the concrete-faced rock-fill dam under complex loading conditions," European Journal of Environmental and Civil Engineering, vol. 17, no. 7, pp. 579-597, 2013.

[23] K. H. Roscoe, A. N. Schofield, and A. Thurairajah, "Yielding of clays in states wetter than critical," Géotechnique, vol. 13, no. 3, pp. 211-240, 1963.

[24] Z. Fu, S. Chen, Q. Zhong, and Y. Zhang, "Modeling interaction between loading-induced and creep strains of rockfill materials using a hardening elastoplastic constitutive model," Canadian Geotechnical Journal, vol. 56, no. 10, pp. 1380-1394, 2019.

[25] S. C. Robert Lo and I. Kenneth Lee, "Response of granular soil along constant stress increment ratio path," Journal of Geotechnical Engineering, vol. 116, no. 3, pp. 355-376, 1990.

[26] M. Xu, E. Song, and J. Chen, "A large triaxial investigation of the stress-path-dependent behavior of compacted rockfill," Acta Geotechnica, vol. 7, no. 3, pp. 167-175, 2012.

[27] M. Liu, Y. Gao, and H. Liu, "An elastoplastic constitutive model for rockfills incorporating energy dissipation of nonlinear friction and particle breakage," International Journal for Numerical and Analytical Methods in Geomechanics, vol. 38, no. 9, pp. 935-960, 2014.

[28] M. Pastor, O. C. Zienkiewicz, and A. H. C. Chan, "Generalized plasticity and the modelling of soil behaviour," International Journal for Numerical and Analytical Methods in Geomechanics, vol. 14, no. 3, pp. 151-190, 1990.

[29] Z. Fu, S. Chen, and C. Peng, "Modeling cyclic behavior of rockfill materials in a framework of generalized plasticity," International Journal of Geomechanics, vol. 14, no. 2, pp. 191-204, 2015. 